\title{
International monetary policy coordination under asymmetric shocks
}

\author{
Carmen Díaz-Roldán ${ }^{1}$ \\ Universidad Pública de Navarra
}

March 2000

\footnotetext{
${ }^{1}$ This paper is a revised version of the second chapter or my Ph. D. Dissertation. I wish to thank the Thesis committee, in particular Juan F. Jimeno, as well as my adviser Oscar Bajo-Rubio, for their helpful suggestions. Previous versions were presented at the International Symposium on Economic Modelling (Vienna, July 1998) and the IV Encontro Galego de Novos Investigadores de Analise Economica (Santiago de Compostela, July 1998). Financial support from the Spanish Ministry of Education through the Project PB98-0546-C02-01, as well as from Fundación de las Cajas de Ahorros Confederadas, is also gratefully acknowledged. Of course, all the remaining errors are my own.
} 


\begin{abstract}
The purpose of this paper is to show whether international policy coordination may be the best response to economic interdependence. We will study the short-run interactions taking place among interdependent economies, where monetary supply is the instrument used to maintain output and price targets. We develop a macroeconomic model in which countries show different preferences regarding objectives and face asymmetric disturbances, analyzing in strategic terms how monetary policy can deal with real, monetary, and supply shocks. We also show how the superiority of the cooperative solution depends on the sources of the disturbances, the underlying economic framework, and the asymmetry of the preferences.
\end{abstract}

Key words: Interdependence, asymmetric shocks, coordination of monetary policies.

JEL Classification: E52, E61, F42. 


\section{Contents}

1 Introduction 2

2 The model 4

2.1 The transmission of the shocks . . . . . . . . . 8

2.1.1 Supply shocks ................ 8

2.1.2 Demand shocks ............... 9

3 Monetary policy coordination $\quad 11$

3.1 The preferences of the countries . . . . . . . . . . . 11

3.2 The optimization problem . . . . . . . . . . . . 12

3.3 The "locomotive effect" . . . . . . . . . . . . . . . 12

3.3.1 Non-cooperative solution: The competitive solution . . 13

3.3.2 Non-cooperative solution: The leader-follower model . 15

3.3.3 Cooperative solution: The social planner problem . . . 16

3.4 The "beggar-thy-neighbour effect" . . . . . . . . . . . . 17

3.4.1 Non-cooperative solution: The competitive solution . . 17

3.4.2 Non-cooperative solution: The leader-follower model . 18

3.4.3 Cooperative solution: The social planner problem . . . 19

4 Welfare aspects of the optimal solution $\quad 19$

4.1 The "locomotive effect" . . . . . . . . . . . . . . . . . 21

4.2 The "beggar-thy-neighbour effect" . . . . . . . . . . 22

4.3 The desirability of monetary policy coordination . . . . . . . 24

5 Conclusions $\quad 28$

6 Appendix 31

References $\quad 40$ 


\section{Introduction}

The greater is the degree of economic integration, the greater are the spillover effects produced when one of the involved economies suffers a shock. The effects of the interaction among interdependent economies depend on the channels of transmission of the shocks. Since the channels of transmission are determined by the economic framework of each country, it is necessary to take into account national policy interactions when adopting economic policy decisions.

Given that the immediate effect of interdependence is a greater policy interaction, the question arises on whether it is possible that international policy coordination may be a better response than non-cooperative solutions. The theoretical arguments supporting policy coordination are based on the idea that cooperation internalizes the effects of economic interdependence, which no government can achieve individually. In this context, must be considered the strategic behaviour of the authorities, so we will use the Game Theory approach to study how authorities can deal with shocks.

The first author using the Game Theory approach to study international policy coordination is Hamada (1976), through a two-country model where governments have as objectives price stability and balance of payments equilibrium. In a system of fixed exchange rates, where the level of credit expansion is the only policy instrument, Hamada shows that the objectives cannot be reached simultaneously. The reason is that the interests of each country would be in conflict, and even with flexible exchange rates the noncooperative solution is suboptimal.

There are a wide range of later contributions examining international cooperation in strategic terms; see, among others, Cooper (1985), Corden $(1985,1986)$, Canzoneri and Gray (1985), Currie and Levine (1986), Kehoe (1987), and Gutiérrez (1993) for a survey. In general, these studies show that when the authorities ignore interdependence, the solutions will not be optimal, concluding that, when authorities cooperate, the result is a Pareto improvement.

These results justify theoretically international policy coordination. But, on the contrary, empirical studies reveal that the benefits from coordination are not very clear [see, among others, Oudiz and Sachs (1984), Frankel and Rockett (1988), and Douven and Plasmans (1995)]. It is found that the benefits from coordination are not greater than those obtained from a simple 
exchange of information. But, under certain circumstances -i.e., when there is a conflict of interests and the interdependence among countries is big enoughbenefits from coordination can be obtained if policy is credible.

In recent years, literature on coordination has recovered a new interest [see, Bryant (1995), Hughes Hallet and Ma (1995), and Sibert (1997)] having in mind the case of the European monetary union. Since monetary union is one of the possible infinite cooperative solutions; consequently, the interest of forming an European monetary union could be interpreted as an explicit way of taking advantages from monetary policy coordination.

The aim of this paper is to show, first of all, how the international economic framework determines the spillover effects of the shocks. And, secondly, to study how policy coordination can internalize these externalities, trying to obtain the conditions under which cooperation would be useful. For this purpose we will develop a two-country model in which countries, with different preferences on output and price targets, suffer asymmetric demandside and supply-side shocks.

On the other hand, recent literature has focused on the effects of asymmetric shocks, since these kind of shocks could difficult the well functioning of the European monetary union. Cohen and Wyplosz (1989), assume the fact that asymmetric shock would produce negative effects on a monetary union. This idea, mentioned in the literature on optimum currency areas (Mundell, 1961), has been studied again more recently (De Grauwe and Vanhaverbeke (1993), Ballabriga, Sebastián and Vallés (1993), ErkelRouse and Mélitz (1995), and Helg et al. (1995), among others). For these reason, we will focus our analysis on the short-run effects of asymmetric shocks, trying to show the conditions that could support monetary policy coordination; and, eventually, the constitution of a monetary union.

In relation with other related studies, the main contribution of this paper is to show how both the effects of the shocks and the policies used to deal with them, depend on the economic framework; and, from here to analyze the possibilities of coordination as a response to shocks. The main conclusion is that the characterization of the shocks as symmetric or asymmetric is a necessary condition but not sufficient in order to determine the desirability of monetary policy coordination. In this sense, the nature (monetary, real or supply-side) of the shock and the asymmetry of the preferences prove to be determinant for the superiority of the cooperative solution. In particular, we obtain that, when dealing with monetary shocks, the cooperative solution results indifferent with independence of the channel of 
transmission. Regarding real shocks, cooperation could be counterproductive under certain circumstances. And finally, we find that monetary policy coordination is always useful when dealing with supply-side shocks.

The paper is structured as follows. In section 2 we develop a theoretical two-country model which will allow us to study the effects of shocks on countries, depending on the channel of transmission of these shocks. Next, in section 3 we analyse in strategic terms how the authorities can deal with shocks using monetary policy with stabilizing purposes. We also show how monetary policy coordination may internalize the spillover effects of an individual decision, and how the superiority of the cooperative solution depends on the sources of the disturbances, the underlying economic framework, and the asymmetry of the preferences. In section 4, we discuss the welfare aspects of the optimal solution. Finally, in section 5 we present the main conclusions.

\section{The model}

We will consider a model of two symmetric economies: the domestic country and the foreign country, with flexible exchange rates and perfect capital mobility between them. All the variables are defined as rates of change and those from the foreign country are denoted with an asterisk.

The domestic country is described by the following set of equations, where all parameters, denoted by Greek letters, are nonnegative:

$$
\begin{gathered}
y=-\alpha r_{\mathrm{w}}+\beta\left(e+p^{*}-p\right)+\delta y^{*}+f \\
m-p=\theta y-\psi r_{\mathrm{w}}-q \\
p_{c}=(1-\mu) p+\mu\left(p^{*}+e\right) \\
w-\varepsilon p_{c}=\phi \text { prod }-\eta u+z-v \\
p-w=-\phi \text { prod }-\varphi u
\end{gathered}
$$




$$
y^{s}=n+\operatorname{prod}
$$

Equation (1) represents the goods market equilibrium condition. Output depends on the world interest rate $r_{\mathrm{w}}$, the real exchange rate $\left(e+p^{*}-p\right)$, the foreign country's output $y^{*}$, and a positive real shock $f$. Notice that the assumption of perfect capital mobility implies that $r=r^{*}=r_{\mathrm{w}}$. We also assume that the Marshall-Lerner condition holds, so that a real exchange rate depreciation leads to a positive effect on the balance of trade and output of the domestic country, which implies $\beta$ to be positive.

Equation (2) shows the money market equilibrium condition, where $m$ denotes the money supply, and the demand for money depends on domestic output, the world interest rate, and a monetary shock $q$.

Equations (3) to (6) represent the aggregate supply of the economy, built along the lines of Layard, Nickell and Jackman's (1991) model, (see also Nickell (1990) for a survey). Equation (3) is the definition of the consumer price index, as a weighted average of the domestic goods' and the imported goods' prices in terms of the domestic currency.

Equation (4) shows that nominal wages are determined by the degree of indexation with respect to the consumer price index, depending on $\varepsilon$; labour productivity, prod; the unemployment rate, $u$; wage pressure factors, $z$; and the way in which agents form their expectations, captured by the variable $v$.

The parameter $\varepsilon$ denotes the degree of wage rigidity, with $0 \leqq \varepsilon \leqq 1$. The value $\varepsilon=1$ implies real wage rigidity, so that nominal wages are fully indexed to changes in the consumer price index $p_{c}$; whereas if $\varepsilon=0$ we have nominal wage rigidity. In our model, we will assume the intermediate case so that $0<\varepsilon<1$.

On the other hand, the effects of expectations on the consumer price index is captured by the variable $v$. In a "New Classical Macroeconomics" framework, assuming rational expectations, the discrepancies between the actual change in the consumer price index and its expected change is due to random agents' mistakes, i.e.: $p_{c}-p_{c}^{e}=$ error, so that $v=\varepsilon$ error , and if error is equal to zero (i.e., the agents do not make mistakes) for $\varepsilon \neq 0$, the unemployment rate obtained from equations (4) and (5) will be the natural rate of unemployment. Alternatively, in a "New Keynesian Macroeconomics" framework, if the agents form their expectations assuming that the expected change of the consumer price index is equal to its change in the previous 
period, $p_{c}^{e}=p_{c,-1}$, then $p_{c}-p_{c}^{e}=p_{c}-p_{c,-1}=\Delta p_{c}$, and the variable $v=\varepsilon \Delta$ $p_{c}$, would capture changes in the inflation rate for the consumer price index. In that case, for $\varepsilon \neq 0$, the unemployment rate obtained from equations (4) and (5) will be the NAIRU. Therefore, this general formulation allows us to include both models (New Classical and New Keynesian) as particular cases.

In equation (5), prices are formed by adding a margin to wages, which depends on productivity, prod, and unemployment rate, $u$. We also assume that the parameter $\phi$ is the same that in the wage equation (4). This assumption, which simplifies the analysis without altering the basic results, is commonly used in the literature, and is justified since in the long term productivity changes do not affect the unemployment rate (see e.g. Layard, Nickell and Jackman (1991)).

Finally, equation (6) defines changes in output as the sum of changes in employment, $n$, and productivity, prod .

Equations describing the foreign country are equivalent to the domestic country's equations. We also assume asymmetric shocks in origin leading to different effects on the involved countries, so we have the following set of equations:

$$
\begin{gathered}
y^{*}=-\alpha r_{\mathrm{W}}-\beta\left(e+p^{*}-p\right)+\delta y+f^{*} \\
m^{*}-p^{*}=\theta y^{*}-\psi r_{\mathrm{W}}-q^{*} \\
p_{c}^{*}=(1-\mu) p^{*}+\mu(p-e) \\
w^{*}-\varepsilon p_{c}^{*}=\phi p r o d^{*}-\eta u^{*}+z^{*}-v^{*} \\
p^{*}-w^{*}=-\phi p r o d^{*}-\varphi u^{*} \\
y^{* s}=n^{*}+\operatorname{prod}^{*}
\end{gathered}
$$

From equations (1) to (6) for the domestic country and (7) to (12) for the foreign country, we can obtain the aggregate demand functions for each economy: 
$y^{d}=\frac{\alpha}{\psi+\alpha \theta}(m-p)+\frac{\beta \psi}{\psi+\alpha \theta}\left(e+p^{*}-p\right)+\frac{\delta \psi}{\psi+\alpha \theta} y^{* d}+\frac{\psi}{\psi+\alpha \theta} f+\frac{\alpha}{\psi+\alpha \theta} q$

$y^{* d}=\frac{\alpha}{\psi+\alpha \theta}\left(m^{*}-p^{*}\right)-\frac{\beta \psi}{\psi+\alpha \theta}\left(e+p^{*}-p\right)+\frac{\delta \psi}{\psi+\alpha \theta} y^{d}+\frac{\psi}{\psi+\alpha \theta} f^{*}+\frac{\alpha}{\psi+\alpha \theta} q^{*}$

Combining the definition of the consumer price index (3) with the aggregate supply equations, (4) to (6), and replacing $u=l-n$ (where $l$ denotes active population), we can obtain the domestic country's aggregate supply:

$$
y^{s}=-\lambda(\varepsilon-1) p-\lambda \varepsilon \mu\left(e+p^{*}-p\right)-\lambda z+\lambda v+l+\operatorname{prod}
$$

where $\lambda=\frac{1}{\eta+\varphi}$.

To simplify, we group all the exogenous supply shocks in a contractionary disturbance $s$ :

$$
s=z-v-\frac{1}{\lambda} l-\frac{1}{\lambda} \operatorname{prod}
$$

where $s$ embodies the negative effect on output of an increase in the degree of wage pressure, $z$; and the positive effects of increases in the expectations errors, $v$; active population, $l$; and productivity, prod.

Then, the aggregate supply of the domestic country will be:

$$
y^{s}=-\lambda(\varepsilon-1) p-\lambda \varepsilon \mu\left(e+p^{*}-p\right)-\lambda s
$$

and, in a similar way, for the foreign country:

$$
y^{* s}=-\lambda(\varepsilon-1) p^{*}+\lambda \varepsilon \mu\left(e+p^{*}-p\right)-\lambda s^{*}
$$

where: $s^{*}=z^{*}-v^{*}-\frac{1}{\lambda} l^{*}-\frac{1}{\lambda} \operatorname{prod}^{*}$ 


\subsection{The transmission of the shocks}

From equations (1) to (6) and (7) to (12), and assuming equilibrium in the goods market: $y^{s}=y^{d}=y$ and $y^{* s}=y^{* d}=y^{*}$, we can obtain the reduced forms for each country (see Appendix A.I).

$$
\begin{aligned}
& y=a m \pm b m^{*}+c f \pm d f^{*}+a q \pm b q^{*}-g s-h s^{*} \\
& y^{*}=a m^{*} \pm b m+c f^{*} \pm d f+a q^{*} \pm b q-g s^{*}-h s \\
& p=i m \pm j m^{*}+k f+l f^{*}+i q \pm j q^{*}+n s+\tilde{n} s^{*} \\
& p^{*}=i m^{*} \pm j m+k f^{*}+l f+i q^{*} \pm j q+n s^{*}+\tilde{n} s
\end{aligned}
$$

The reduced form given by equations (17) to (20) shows the interdependence between the two economies, given by the interaction of the variables.

\subsubsection{Supply shocks}

Solving the model, we find that a negative supply shock leads to an output fall and a rise in prices in both countries. This effect is independent of the channel of transmission of the shock.

The supply shocks multipliers are as follows:

$$
\begin{gathered}
\frac{\partial y}{\partial s}=\frac{\partial y^{*}}{\partial s^{*}}=-g \\
\frac{\partial p}{\partial s}=\frac{\partial p^{*}}{\partial s^{*}}=n \\
\frac{\partial y}{\partial s^{*}}=\frac{\partial y^{*}}{\partial s}=-h \\
\frac{\partial p}{\partial s^{*}}=\frac{\partial p^{*}}{\partial s}=\tilde{n}
\end{gathered}
$$




\subsubsection{Demand shocks}

Positive demand shocks lead to positive effects on the output and prices of the country of origin of the shock. But when the shock is transmitted across the two countries, the sign of the coefficients depends on which channel of transmission prevails.

In our model, the channels of transmission of the demand shocks are the aggregate demand, the interest rate, the real exchange rate, and the countries' relative prices. When aggregate demand prevails, the result is the "locomotive effect": the effects on the output and prices of the country of origin of the shock are transmitted to the other country with the same sign. But when changes in the interest rate and real exchange rate prevail, the result is the "beggar-thy-neighbour effect": the effects on the output and prices of the country of origin of the shock are transmitted to the other country with the opposite sign. The reason is that a real exchange rate depreciation (appreciation) in an economy leads to an aggregate demand expansion (contraction) in that economy, and to a contraction (expansion) in the other, given that which means a depreciation (appreciation) for an economy, means an appreciation (depreciation) for the other.

The "locomotive effect" An increase in the money supply $(m>0)$, a positive monetary shock in general $(q>0)$, and a positive real shock $(f>0)$ lead to an increase in output. The result is an aggregate demand expansion with an output expansion an a rise in prices in the two countries.

The monetary multipliers are as follows:

$$
\begin{gathered}
\frac{\partial y}{\partial m}=\frac{\partial y^{*}}{\partial m^{*}}=\frac{\partial y}{\partial q}=\frac{\partial y^{*}}{\partial q^{*}}=a \\
\frac{\partial p}{\partial m}=\frac{\partial p^{*}}{\partial m^{*}}=\frac{\partial p}{\partial q}=\frac{\partial p^{*}}{\partial q^{*}}=i \\
\frac{\partial y}{\partial m^{*}}=\frac{\partial y^{*}}{\partial m}=\frac{\partial y}{\partial q^{*}}=\frac{\partial y^{*}}{\partial q}=b \\
\frac{\partial p}{\partial m^{*}}=\frac{\partial p^{*}}{\partial m}=\frac{\partial p}{\partial q^{*}}=\frac{\partial p^{*}}{\partial q}=j
\end{gathered}
$$

and the multipliers of the real shocks: 


$$
\begin{gathered}
\frac{\partial y}{\partial f}=\frac{\partial y^{*}}{\partial f^{*}}=c \\
\frac{\partial p}{\partial f}=\frac{\partial p^{*}}{\partial f^{*}}=k \\
\frac{\partial y}{\partial f^{*}}=\frac{\partial y^{*}}{\partial f}=d \\
\frac{\partial p}{\partial f^{*}}=\frac{\partial p^{*}}{\partial f}=l
\end{gathered}
$$

The "beggar-thy-neighbour effect" An increase in the money supply of the domestic country $(m>0)$ or a positive monetary shock $(q>0)$, increase output and leads to an exchange rate depreciation. The result is the "beggarthy-neighbour effect": output and prices rise in the domestic country, but output and prices fall in the foreign country.

The monetary multipliers are the following:

$$
\begin{gathered}
\frac{\partial y}{\partial m}=\frac{\partial y^{*}}{\partial m^{*}}=\frac{\partial y}{\partial q}=\frac{\partial y^{*}}{\partial q^{*}}=a \\
\frac{\partial p}{\partial m}=\frac{\partial p^{*}}{\partial m^{*}}=\frac{\partial p}{\partial q}=\frac{\partial p^{*}}{\partial q^{*}}=i \\
\frac{\partial y}{\partial m^{*}}=\frac{\partial y^{*}}{\partial m}=\frac{\partial y}{\partial q^{*}}=\frac{\partial y^{*}}{\partial q}=-b \\
\frac{\partial p}{\partial m^{*}}=\frac{\partial p^{*}}{\partial m}=\frac{\partial p}{\partial q^{*}}=\frac{\partial p^{*}}{\partial q}=-j
\end{gathered}
$$

On the other hand, a positive real shock to the domestic country $(f>0)$ leads to an increase in aggregate demand that is partially offset by a real exchange rate appreciation. This appreciation reduces aggregate supply in the foreign country, which translates to the domestic country. The result is that the output of the country suffering the shock rises, and the output of the other country falls, with prices always rising.

The multipliers are now the following:

$$
\frac{\partial y}{\partial f}=\frac{\partial y^{*}}{\partial f^{*}}=c
$$




$$
\begin{gathered}
\frac{\partial p}{\partial f}=\frac{\partial p^{*}}{\partial f^{*}}=k \\
\frac{\partial y}{\partial f^{*}}=\frac{\partial y^{*}}{\partial f}=-d \\
\frac{\partial p}{\partial f^{*}}=\frac{\partial p^{*}}{\partial f}=l
\end{gathered}
$$

\section{Monetary policy coordination}

In the previous section we have studied the transmission of macroeconomic shocks affecting interdependent economies, and the extent to which the monetary policy adopted by the countries' governments generates disturbances in the other country. The purpose of this section is to show how international policy coordination may internalize these spillover effects. The theoretical arguments supporting policy coordination are based on the idea that cooperation internalizes the effects of economic interdependence. In this context we need to take into account the strategic behaviour of the authorities, so we will use the Game Theory approach in order to study how the authorities can deal with shocks.

\subsection{The preferences of the countries}

We assume that the countries are represented by their authorities, which face the problem of minimizing their loss functions:

$$
\begin{gathered}
L=y^{2}+\sigma p^{2} \\
L^{*}=y^{* 2}+\sigma^{*} p^{* 2}
\end{gathered}
$$

where the target variables are the rates of change in output, $\left(y, y^{*}\right)$, and the rate of change in prices, $\left(p, p^{*}\right)$. The parameters $\sigma>0$ and $\sigma^{*}>0$ are the inverse of the marginal substitution rates, i.e., the cost of reaching an objective relative to the cost of reaching the other. On the other hand, the quadratic form of the loss function implies that any change, positive or negative, in the variables will represent a loss of utility. So, each country will 
minimize its loss function when all the objectives are equal to zero, $y=y^{*}=0$ and $p=p^{*}=0$.

\subsection{The optimization problem}

In this subsection we will show the effects of monetary authorities' decisions when they cope with shocks. For this reason, we will analyse how they will react when facing shocks that affect both the money market $\left(m, m^{*}, q, q^{*}\right)$ and the goods market $\left(f, f^{*}\right)$, shifting the aggregate demand curve; and when facing supply shocks $\left(s, s^{*}\right)$, which shift the aggregate supply curve.

Each monetary authority has to minimize its loss function by choosing the optimal rate of change of the money supply, subject to the restrictions imposed by the international economic framework. According to the Game Theory literature, there are three possibilities to solve the problem: the competitive equilibrium, the leader-follower model and the cooperative solution. But the solutions will depend on the prevailing channel of transmission: the aggregate demand, or the interest rate and the real exchange rate. So, we will solve the problem for these two alternative cases.

\subsection{The "locomotive effect"}

When aggregate demand is the prevailing channel of transmission, the restrictions that fiscal authorities have to take into account when solving their optimization problem are as follows:

$$
\begin{gathered}
y=a m+b m^{*}+c f+d f^{*}+a q+b q^{*}-g s-h s^{*} \\
y^{*}=a m^{*}+b m+c f^{*}+d f+a q^{*}+b q-g s^{*}-h s \\
p=i m+j m^{*}+k f+l f^{*}+i q+j q^{*}+n s+\tilde{n} s^{*} \\
p^{*}=i m^{*}+j m+k f^{*}+l f+i q^{*}+j q+n s^{*}+\tilde{n} s
\end{gathered}
$$




\subsubsection{Non-cooperative solution: The competitive solution}

When each country solves the problem individually, ignoring interdependence and taking as given the other country's policy, the solution is the NashCournot Equilibrium. The optimization problem of the domestic country is as follows:

$$
\begin{aligned}
\min _{m} L= & y^{2}+\sigma p^{2} \\
& \text { s.t. }(43),(45)
\end{aligned}
$$

From the first-order condition we obtain the reaction function of the domestic country, which shows the response to shocks and to changes in the foreign country's policy. We have modelled a loss function in which each country shows a greater or lower aversion to changes in prices with respect to changes in output $\left(\sigma, \sigma^{*} \gtrless 1\right)$. Given that the coefficients of the reaction function depend on $\sigma$ (see Appendix A.II), we will obtain two reaction functions depending on the countries' preferences.

When $(\sigma>1)$, changes on prices represent a loss of utility for the domestic country. For this reason, it would prefer to maintain prices instead of output, so the reaction function will be:

$$
m_{p}=-R_{p, 1} m^{*}-R_{p, 2} f-R_{p, 3} f^{*}-q-R_{p, 1} q^{*}-R_{p, 4} s-R_{p, 5} s^{*}
$$

On the contrary, when $(\sigma<1)$, the country would prefer to maintain output and the reaction function will be:

$$
m_{y}=-R_{y, 1} m^{*}-R_{y, 2} f-R_{y, 3} f^{*}-q-R_{y, 1} q^{*}+R_{y, 4} s+R_{y, 5} s^{*}
$$

The problem for the foreign country is similar:

$$
\begin{aligned}
\min _{m^{*}} L^{*}= & y^{* 2}+\sigma^{*} p^{* 2} \\
& \text { s.t. }(44),(46)
\end{aligned}
$$

from which we can obtain, for $\sigma^{*}>1$ and $\sigma^{*}<1$ respectively: 


$$
\begin{aligned}
& m_{p}^{*}=-R_{p, 1}^{*} m-R_{p, 2}^{*} f-R_{p, 3}^{*} f^{*}-R_{p, 1}^{*} q-q^{*}-R_{p, 4}^{*} s-R_{p, 5}^{*} s^{*} \\
& m_{y}^{*}=-R_{y, 1}^{*} m-R_{y, 2}^{*} f-R_{y, 3}^{*} f^{*}-R_{y, 1}^{*} q-q^{*}+R_{y, 4}^{*} s+R_{y, 5}^{*} s^{*}
\end{aligned}
$$

The absolute value of each coefficient indicates the size of the response to shocks. When a country suffers a monetary disturbance ( $q$ or $\left.q^{*}\right)$, the change in money supply has the same size but opposite sign (coefficient equal to -1 ) than the shock. Consequently, this monetary policy would offset the effects of the shock. Regarding real and supply disturbances, none of them is totally offset, because $|R|<1$.

Both reaction functions have negative slopes. The domestic country's reaction function has a slope greater than one in absolute value: $\left.\frac{d m^{*}}{d m}\right|_{m=R\left(m^{*}\right)}=-\frac{1}{R_{1}}$, with $\left|-\frac{1}{R_{1}}\right|>1$. This means that any movement along the domestic country's reaction function, requires a lower change in money supply in the domestic country than in the foreign one. Solving their problems individually, and ignoring interdependence, if a country minimizes changes in its money supply this requires a greater variation in the other country's money supply. We can see from the loss functions -equations (41) and (42)- that any deviation from zero, $y=y^{*}=0$ and $p=p^{*}=0$, will represent a loss of utility. When a country suffers a shock, the bliss points are given by $B=\left(0, m^{*} \neq 0\right)$ and $B^{*}=(m \neq 0,0)$ which are the origin of the indifference curves. The countries would achieve the maximum welfare in these points because they would not have to change their money supplies, but conflict arises since the two points do not coincide.

Given that we have assumed flexible exchange rates, each country can use its monetary policy instrument individually. The Nash-Cournot equilibrium is given by the intersection of the countries' reaction functions. In our case, since we consider asymmetric preferences $\sigma \neq \sigma^{*}$, there are four possibilities:

a) $\sigma>1, \sigma^{*}>1$ : both countries are interested in maintaining prices. Solving the equations (48) and (51), we get that, following a rise in prices, the optimal policy would be a contractionary monetary policy.

b) $\sigma<1, \sigma^{*}<1$ : both countries prefer to maintain output. Solving the equations (49) and (52), the optimal policy would be a contractionary monetary policy to offset an output expansion, and a expansionary monetary policy to offset an output contraction. 
c) $\sigma>1, \sigma^{*}<1$ : the domestic country prefers to maintain prices, and the foreign country prefers to maintain output. The optimal response is given by the solutions to equations (48) and (52).

d) $\sigma<1, \sigma^{*}>1$ : the domestic country prefers to maintain output, and the foreign country prefers to maintain prices. The optimal response is given by the solutions to equations (49) and (51).

In the cases c) and d) the country interested in prices would always use contractionary monetary policies. But the country interested in output would use contractionary monetary policies when dealing with demand shocks, and expansionary monetary policies when dealing with supply shocks.

Given that we would like to analyse how the countries react to specific shocks, we will consider the most asymmetric case. So, we will study case d) where the domestic country prefers to maintain output and the foreign country prices. The Nash solution is the point where the reaction functions of each country intersect:

$$
\begin{gathered}
m_{N}=-q-N_{1} f-N_{2} f^{*}+N_{3} s+N_{4} s^{*} \\
m_{N}^{*}=-q^{*}-N_{1}^{*} f-N_{2}^{*} f^{*}-N_{3}^{*} s-N_{4}^{*} s^{*}
\end{gathered}
$$

It can be proved (see Appendix A.III) that the coefficients of the Nash solution are lower, in absolute value, than the coefficients of the reaction function. That is, when solving the problem individually each country acts in a "myopic" way and, since interdependence is ignored, the effects of monetary policy are transmitted abroad.

\subsubsection{Non-cooperative solution: The leader-follower model}

When one of the countries acts as a leader and the other as a follower, the result is a Nash-Stackelberg Equilibrium. The leader chooses first taking into account its own interest and the foreign country's reaction function, which the leader includes in its loss function. If the foreign country (interested in maintaining prices) acts as leader, then its optimization problem is given by:

$$
\min _{m^{*}} L^{*}=L^{*}\left(y^{*}, p^{*}, m_{y}\right)
$$

so, it will have to solve: 


$$
\begin{aligned}
\min _{m^{*}} L^{*}= & y^{* 2}+\sigma^{*} p^{* 2} \\
& \text { s.t. }(44),(46),(49)
\end{aligned}
$$

obtaining from the first-order condition:

$$
m_{S}^{*}=-q^{*} \pm S_{1}^{*} f \pm S_{2}^{*} f^{*} \pm S_{3}^{*} s \pm S_{4}^{*} s^{*}
$$

The previous equation represents changes in the money supply of the leader. The follower takes it into account to solve its own problem:

$$
\begin{aligned}
\min _{m} L= & y^{2}+\sigma p^{2} \\
& \text { s.t. }(43),(45),(57)
\end{aligned}
$$

obtaining:

$$
m_{S}=-q \pm S_{1} f \pm S_{2} f^{*} \pm S_{3} s \pm S_{4} s^{*}
$$

The ambiguity of the signs indicates that the best policy response, expansionary or contractionary, will depend on the value of the coefficients involved in the solution. In any case, the change in the leader's money supply is lower than that of the follower (see in Appendix A.IV that $\left|S_{i}\right|>\left|S_{i}^{*}\right|$ for $i=1, \ldots, 4)$. Choosing first, the leader has a time advantage and the follower's response requires a greater change in its money supply. Because of that, the Stackelberg equilibrium is not always a Pareto improvement upon the Nash equilibrium. The leader is always better off than in the competitive solution, but the final result for the follower is ambiguous. Moreover, the solution is unstable because the leader is not on its reaction function.

\subsubsection{Cooperative solution: The social planner problem}

If the countries coordinate their policies, they minimize the weighted sum of their loss functions. Given the assumption of symmetry, and with the weights of each country equal to $\frac{1}{2}$, the social planner problem would be:

$$
\begin{aligned}
\min _{m, m^{*}} \mathfrak{L}= & {\left[\frac{1}{2}\left(y^{2}+\sigma p^{2}\right)+\frac{1}{2}\left(y^{* 2}+\sigma^{*} p^{* 2}\right)\right] } \\
& \text { s.t. }(43) \text { to }(46)
\end{aligned}
$$


From the first-order conditions we obtain (see Appendix A.V):

$$
\begin{gathered}
m_{C}=-q-C_{1} f-C_{2} f^{*} \pm C_{3} s \pm C_{4} s^{*} \\
m_{C}^{*}=-q^{*}-C_{1}^{*} f-C_{2}^{*} f^{*} \pm C_{3}^{*} s \pm C_{4}^{*} s^{*}
\end{gathered}
$$

\subsection{The "beggar-thy-neighbour effect"}

When the interest rate and the exchange rate act as the prevailing channels of transmission, the restrictions that the authorities have to take into account to solve their optimization problem are as follows.

$$
\begin{gathered}
y=a m-b m^{*}+c f-d f^{*}+a q-b q^{*}-g s-h s^{*} \\
y^{*}=a m^{*}-b m+c f^{*}-d f+a q^{*}-b q-g s^{*}-h s \\
p=i m-j m^{*}+k f+l f^{*}+i q-j q^{*}+n s+\tilde{n} s^{*} \\
p^{*}=i m^{*}-j m+k f^{*}+l f+i q^{*}-j q+n s^{*}+\tilde{n} s
\end{gathered}
$$

\subsubsection{Non-cooperative solution: The competitive solution}

The Nash-Cournot Equilibrium of the domestic country is given by:

$$
\begin{aligned}
\min _{m} L= & y^{2}+\sigma p^{2} \\
& \text { s.t. }(63),(65)
\end{aligned}
$$

and from the first-order conditions, for $\sigma>1$ and $\sigma<1$, we obtain the reaction functions (see Appendix A.II):

$$
\begin{gathered}
m_{p}^{\prime}=R_{p, 1}^{\prime} m^{*}-R_{p, 2}^{\prime} f-R_{p, 3}^{\prime} f^{*}-q+R_{p, 1}^{\prime} q^{*}-R_{p, 4}^{\prime} s-R_{p, 5}^{\prime} s^{*} \\
m_{y}^{\prime}=R_{y, 1}^{\prime} m^{*}-R_{y, 2}^{\prime} f+R_{y, 3}^{\prime} f^{*}-q+R_{y, 1}^{\prime} q^{*}+R_{y, 4}^{\prime} s+R_{y, 5}^{\prime} s^{*}
\end{gathered}
$$


The problem is similar for the foreign country:

$$
\begin{aligned}
\min _{m^{*}} L^{*}= & y^{* 2}+\sigma p^{* 2} \\
& \text { s.t. }(64),(66)
\end{aligned}
$$

from which we obtain, for $\sigma^{*}>1$ and $\sigma^{*}<1$, respectively:

$$
\begin{aligned}
& m_{p}^{\prime *}=R_{p, 1}^{\prime *} m-R_{p, 2}^{\prime *} f-R_{p, 3}^{\prime *} f^{*}+R_{p, 1}^{\prime *} q-q^{*}-R_{p, 4}^{\prime *} s-R_{p, 5}^{\prime *} s^{*} \\
& m_{y}^{\prime *}=R_{y, 1}^{\prime *} m+R_{y, 2}^{\prime *} f-R_{y, 3}^{\prime *} f^{*}+R_{y, 1}^{\prime *} q-q^{*}+R_{y, 4}^{\prime *} s+R_{y, 5}^{\prime *} s^{*}
\end{aligned}
$$

In this case, the reaction functions have positive slopes, being the slope of the reaction function of the domestic country greater than one. The Nash solution is given by the following equations (see Appendix A.III):

$$
\begin{gathered}
m_{N}^{\prime}=-q-N_{1}^{\prime} f+N_{2}^{\prime} f^{*}+N_{3}^{\prime} s+N_{4}^{\prime} s^{*} \\
m_{N}^{\prime *}=-q^{*}-N_{1}^{\prime *} f-N_{2}^{\prime *} f^{*}-N_{3}^{\prime *} s-N_{4}^{\prime *} s^{*}
\end{gathered}
$$

\subsubsection{Non-cooperative solution: The leader-follower model}

Assuming, again, that the foreign country (interested in maintaining prices) acts as the leader the problem to solve will be:

$$
\begin{aligned}
\min _{m^{*}} L^{*}= & y^{* 2}+\sigma^{*} p^{* 2} \\
& \text { s.t. }(64),(66),(69)
\end{aligned}
$$

obtaining from the first-order condition:

$$
m_{S}^{*}=-q^{*} \pm S_{1}^{\prime *} f \pm S_{2}^{\prime *} f^{*} \pm S_{3}^{\prime *} s \pm S_{4}^{\prime *} s^{*}
$$

The follower takes this solution into account to solve its own problem: 


$$
\begin{aligned}
\min _{m} L= & y^{2}+\sigma p^{2} \\
& \text { s.t. }(63),(65),(76)
\end{aligned}
$$

obtaining therefore:

$$
m_{S}^{\prime}=-q \pm S_{1}^{\prime} f \pm S_{2}^{\prime} f^{*} \pm S_{3}^{\prime} s \pm S_{4}^{\prime} s^{*}
$$

In the same way as in the "locomotive effect" case, the ambiguity of the signs indicates that the best policy response, expansionary or contractionary, will depend on the value of the involved coefficients. The leader has a time advantage and its money supply has to change less, in absolute value, than the follower's money supply (see in Appendix A.IV that $\left|S_{i}^{\prime}\right|<\left|S_{i}^{\prime *}\right|$ for $i=1, \ldots, 4)$.

\subsubsection{Cooperative solution: The social planner problem}

Choosing again weights equal to $\frac{1}{2}$, the problem would be:

$$
\begin{aligned}
\min _{m, m^{*}} \mathfrak{L}= & {\left[\frac{1}{2}\left(y^{2}+\sigma p^{2}\right)+\frac{1}{2}\left(y^{* 2}+\sigma^{*} p^{* 2}\right)\right] } \\
& \text { s.a. }(63) \text { to }(66)
\end{aligned}
$$

From the first-order conditions we obtain (see Appendix A.V):

$$
\begin{gathered}
m_{C}^{\prime}=-q-C_{1}^{\prime} f+C_{2}^{\prime} f^{*} \pm C_{3}^{\prime} s \pm C_{4}^{\prime} s^{*} \\
m_{C}^{\prime *}=-q^{*}+C_{1}^{\prime *} f-C_{2}^{\prime *} f^{*} \pm C_{3}^{\prime *} s \pm C_{4}^{\prime *} s^{*}
\end{gathered}
$$

\section{Welfare aspects of the optimal solution}

Theoretically, the cooperative solution is Pareto improving since it internalizes the spillover effects arising from economic interdependence. These externalities, $\frac{\partial L}{\partial m^{*}}$ and $\frac{\partial L^{*}}{\partial m}$, show how the loss function of a country changes in response to changes in the other country's instrument. For 
that reason cooperation is Pareto improving, since the competitive solution neglects the externalities produced by changes in the policy instrument.

On the one hand, the first-order conditions from which we have obtained the Nash Equilibrium are $\frac{d L}{d m}=0$ and $\frac{\partial L^{*}}{\partial m^{*}}=0$. But for these points $\frac{\partial L}{\partial m^{*}} \neq 0$ and $\frac{\partial L^{*}}{\partial m} \neq 0$. On the other hand, the first-order conditions of the social planner problem are:

$$
\begin{gathered}
\frac{\partial \mathfrak{L}}{\partial m}=\frac{1}{2}\left(\frac{\partial L}{\partial m}+\frac{\partial L^{*}}{\partial m}\right)=0 \\
\frac{\partial \mathfrak{L}}{\partial m^{*}}=\frac{1}{2}\left(\frac{\partial L^{*}}{\partial m^{*}}+\frac{\partial L}{\partial m^{*}}\right)=0
\end{gathered}
$$

From these conditions it is clear that $\frac{\partial L}{\partial m}=-\frac{\partial L^{*}}{\partial m}$ and $\frac{\partial L^{*}}{\partial m^{*}}=-\frac{\partial L}{\partial m^{*}}$, which shows how the cooperative solution internalizes externalities. But the desirability of the cooperative solution will depend on the nature of the externality since, if this externality has the same sign than the shock, the cooperative solution does not offset the adverse effects. Subsequently, we can conclude that cooperation may be counterproductive when it internalizes spillover effects which reinforce the effects of the shock.

In order to avoid the spillover effects of their policies, countries' authorities will try to minimize the use of the money supply. In this sense, they identify stabilization with avoiding changes in the policy instrument. In particular, we have modelled a loss function in which any change in the variables implies a loss of utility. Since the target variables are linear in the policy instruments, the solution that requires a lower change in the money supply would be the optimal solution. So, in a first step, authorities will minimize their loss function, and, in a second step, they will choose the solution (competitive or cooperative) with the lowest absolute value:

$$
m=\arg \min \left\{\left|m_{N, i}\right|,\left|m_{C, i}\right|\right\} \quad \forall i=1,2
$$

It is difficult to know the size of the coefficients of the solutions, since they depend on the coefficients of the reduced form -equations (17) to (20). For that reason, in order to compare the Nash solution with the cooperative solution we will make use of graphical analysis. We will take into account both the slope of the reaction functions (negative for the "locomotive effect", and positive for the "beggar-thy-neighbour effect"), and the sign of the solutions. 


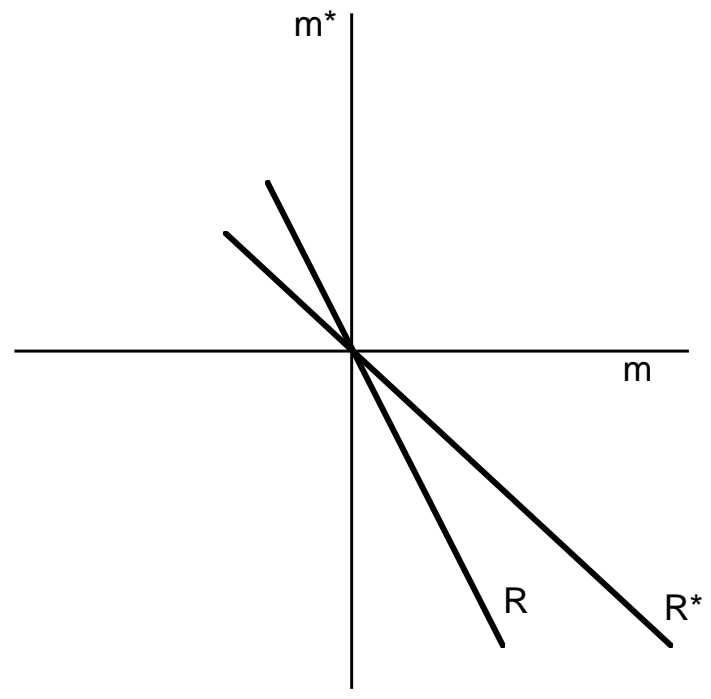

Figure 1: "Locomotive effect". Reaction functions in absence of shocks.

\subsection{The "locomotive effect"}

From the reduced form -equations (17) to (20)- we can see that the objective variables $\left(y, y^{*}, p, p^{*}\right)$ are linear in the policy instruments $\left(m, m^{*}\right)$. Because of that, we can plot both the reaction functions and the indifference curves in the same $m-m^{*}$ plane. For simplicity, we will not show the indifference curves.

For the "locomotive effect", the reaction functions have negative slopes. Figure 1 shows that the reaction functions intersect at the origin: none of the countries has to change its money supply in that point, since there are no shocks. If any disturbance takes place, the reaction functions would shift to the left or to the right according to the particular type of shock.

Figure 2 shows the reaction functions after a monetary shock in the domestic country. The reaction functions shift to the left, being larger the movement for the country suffering the shock, and the bliss points are $B=\left(0, m^{*} \neq 0\right)$ and $B^{*}=(m \neq 0,0)$ respectively.

The Nash solution is at point $N=(-q, 0)$, where the reaction functions intersect. In particular, at point $C$ cooperation results indifferent, since it coincides with the competitive solution $|N|=|C|$, as can be seen from equations (53), (54) and (61), (62). 


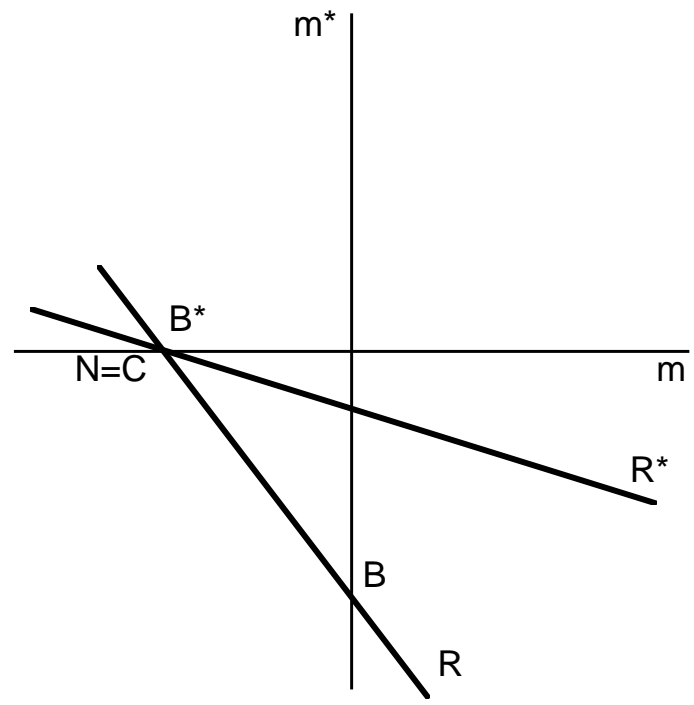

Figure 2: Monetary shock. Cooperation indifferent without "monetary union"; but useful for the country suffering the shock in a "monetary union".

If we depict the case of a real shock, the reaction functions shift to the left. The Nash solution is at point $N=(-q, 0)$, where the reaction functions intersect. Cooperative solution will lie on the contract curve linking $B$ and $B^{*}$. There are infinite cooperative solutions, but we can focus on the case in which both countries react in the same way, $m_{C}=m_{C}^{*}$. In a symmetric model, with the same bargaining weights for each country, it is reasonable to assume that the gains and losses from cooperation would be divided equally. In that case, the solution -which is the most symmetric possible- is given by point C. As we can see from Figure 3, the cooperative symmetric case, at point $C$, requires a greater change in money supply than the Nash solution.

But when dealing with supply-side shocks, the cooperative solution implies a lower change in money supply (see Figure 4). consequently, for the "locomotive effect", cooperation would be useful to offset supply shocks.

\subsection{The "beggar-thy-neighbour effect"}

For the "beggar-thy-neighbour effect", the reaction functions have positive slopes. Figure 5 shows that the reaction functions intersect at the origin, where none of the countries has to change its money supply. 


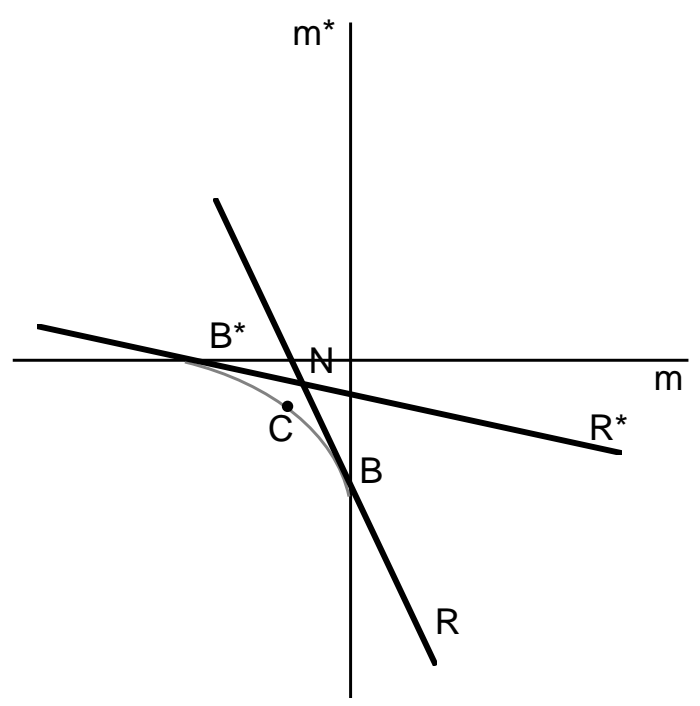

Figure 3: Real shock. Cooperation counterproductive.

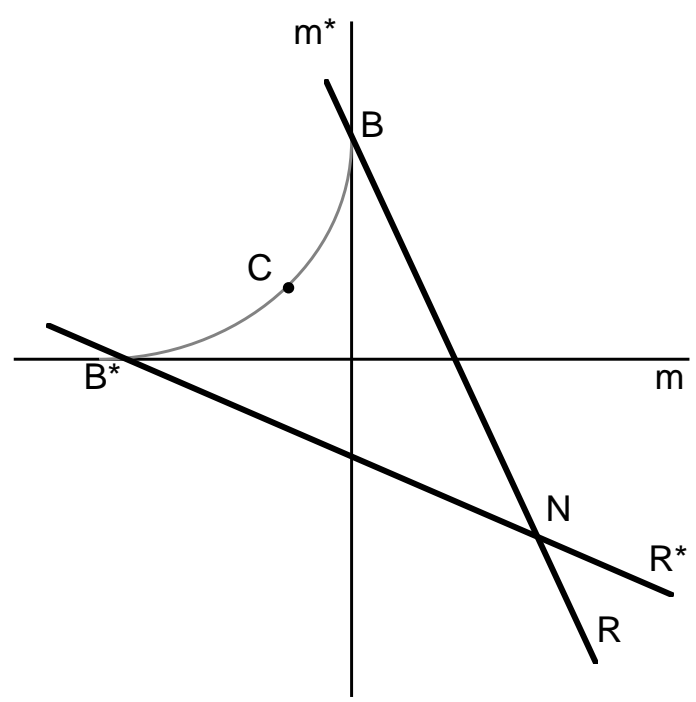

Figure 4: Supply shock. Cooperation useful. 


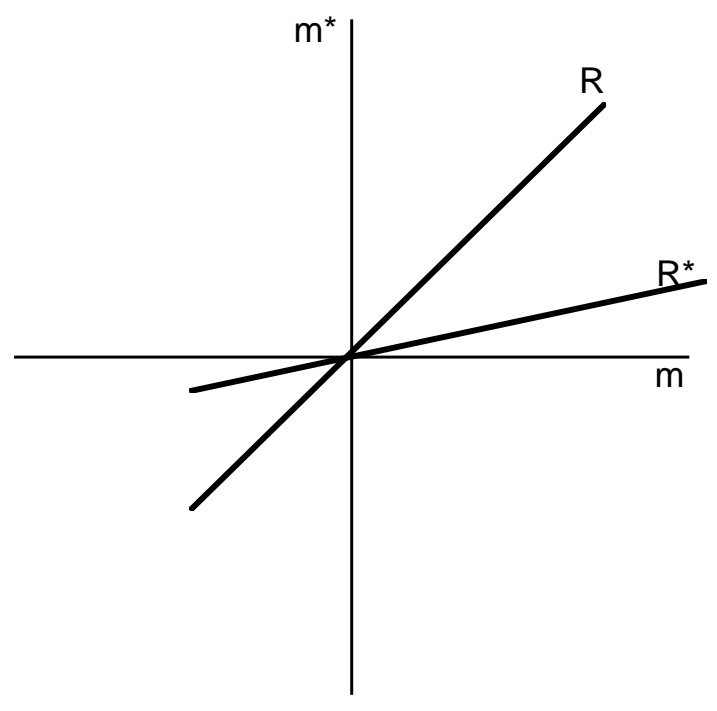

Figure 5: "The beggar-thy-neighbour". Reaction functions in absence of shocks.

In the case of a monetary shock (see Figure 6), the results are equivalent to those for the "locomotive effect". So, cooperation results indifferent.

For a real shock, cooperation is counterproductive only when the foreign country is the only one suffering the shock (see Figures 7 and 8). This result holds with independence of the type of agreement.

When countries suffer supply-side shocks, cooperation requires a greater change in the money supply. Therefore, cooperation results counterproductive.

\subsection{The desirability of monetary policy coordination}

From the results obtained in the previous subsections, we can establish a comparison between the Nash solution and the Cooperative solution. This comparison is shown in Tables 4.1 and 4.2, where we provide the effect (expansionary, contractionary, ambiguous or zero) of the monetary policy used to cope with shocks, depending on the channel of transmission of the shocks. 


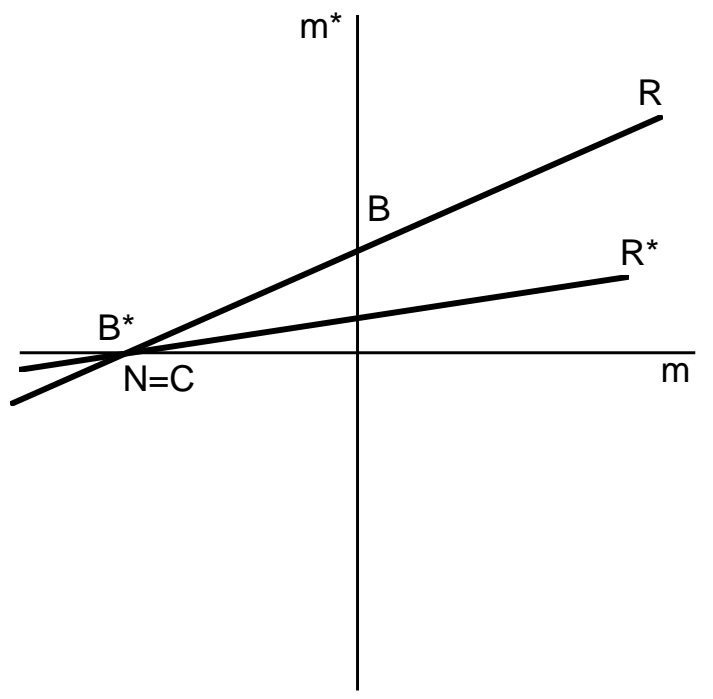

Figure 6: Monetary shock. Cooperation indifferent without "monetary union"; but useful for the country suffering the shock in a "monetary union".

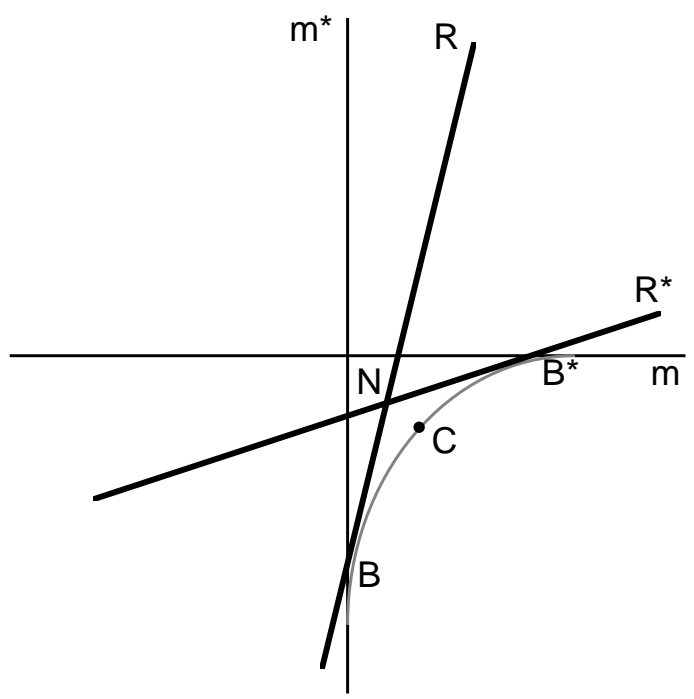

Figure 7: Real shock. Cooperation counterproductive for $\mathrm{f}^{*}$. 


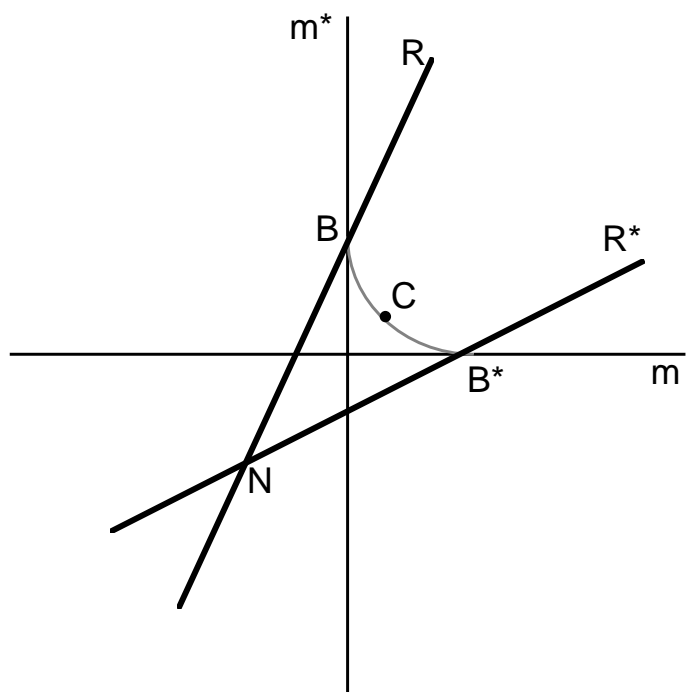

Figure 8: Real shock. Cooperation useful for $\mathrm{f}$ or $\mathrm{f}, \mathrm{f}^{*}$.

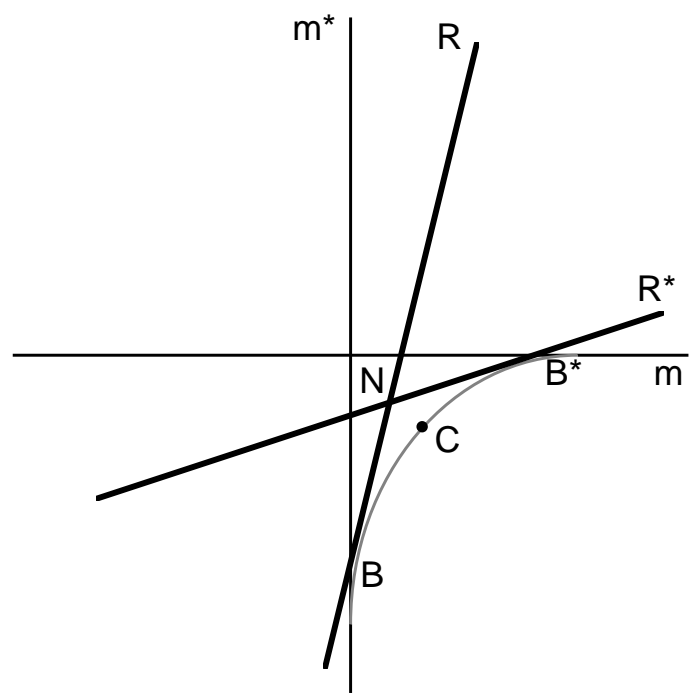

Figure 9: Supply shock. Cooperation counterproductive. 
TABLE 4.1

MONETARY POLICY FROM THE DOMESTIC COUNTRY

"LOCOMOTIVE" "BEGGAR-THY-NEIGHBOUR"

\begin{tabular}{|c||c|c|c||c|c|c|}
\hline Nature of the shock & $\mathrm{R}$ & $\mathrm{N}$ & $\mathrm{C}$ & $\mathrm{R}$ & $\mathrm{N}$ & $\mathrm{C}$ \\
\hline \hline$q$ & - & - & - & - & - & - \\
\hline$q^{*}$ & - & 0 & 0 & + & 0 & 0 \\
\hline$f$ & - & - & - & - & - & - \\
\hline$f^{*}$ & - & - & - & + & + & + \\
\hline$s$ & + & + & \pm & + & + & \pm \\
\hline$s^{*}$ & + & + & \pm & + & + & \pm \\
\hline
\end{tabular}

Notes: a) R, N and $\mathrm{C}$ denote reaction function, Nash solution and Cooperative solution, respectively.

b) $(+),(-),( \pm)$ and 0 denote the sign of the policy.

TABLE 4.2

MONETARY POLICY FROM THE FOREIGN COUNTRY

"LOCOMOTIVE" "BEGGAR-THY-NEIGHBOUR"

\begin{tabular}{|c||c|c|c||c|c|c|}
\hline Nature of the shock & $\mathrm{R}$ & $\mathrm{N}$ & $\mathrm{C}$ & $\mathrm{R}$ & $\mathrm{N}$ & $\mathrm{C}$ \\
\hline \hline$q$ & - & 0 & 0 & + & 0 & 0 \\
\hline$q^{*}$ & - & - & - & - & - & - \\
\hline$f$ & - & - & - & - & - & + \\
\hline$f^{*}$ & - & - & - & + & - & - \\
\hline$s$ & - & - & \pm & - & - & \pm \\
\hline$s^{*}$ & - & - & \pm & - & - & \pm \\
\hline
\end{tabular}

Notes: see Table 4.1 
Summarising the results obtained, we could derive the conditions under which coordination of monetary policy may be useful. These conditions are presented in Table 4.3. From Table 4.3 we can conclude that the results are determined not only by the asymmetry of the shock, but by its nature (monetary, real or supply). When facing monetary shocks, cooperation always results indifferent. But when dealing with real and supply shocks, the channel of transmission proves to be determinant.

TABLE 4.3

DESIRE ABILITY OF MONETARY POLICY COORDINATION

\begin{tabular}{|c|c|}
\hline SHOCK & COOPERATION \\
\hline Monetary $\left(q, q^{*}\right)$ & Indifferent. \\
\hline $\operatorname{Real}\left(f, f^{*}\right)$ & $\begin{array}{l}\text { - "Locomotive effect": } \frac{\text { counterproductive. }}{\text { - "Beggar-thy-neighbour effect": counterproductive when the shock }} \\
\text { has its origin in the foreign country, and useful for the rest of the cases. }\end{array}$ \\
\hline Supply $\left(s, s^{*}\right)$ & $\begin{array}{l}\text { - "Locomotive effect": useful. } \\
\text { •"Beggar-thy-neighbour effect": counterproductive. }\end{array}$ \\
\hline
\end{tabular}

\section{Conclusions}

In this paper, we have tried to study the conditions under which monetary policy coordination would be useful when dealing with asymmetric shocks. For this purpose we have developed a two-country model in which countries, assumed to have different preferences on output and price targets, suffer asymmetric demand-side and supply-side shocks.

By analysing the equilibrium values of the target variables, we have studied both the effects of the shocks and the economic policies used to counteract them. In our model, supply-side shocks have unambiguous effects on target variables. On the contrary, the effects of demand-side shocks depend on the channel of transmission: when aggregate demand prevails, the result is the "locomotive effect", whereas if changes in the interest rate and real exchange rate prevail, the result is the "beggar-thy-neighbour effect". 
Next, we have tried to study which could be the optimal economic policies to offset the effects of the shocks. For this reason we analysed, in strategic terms, how the countries' authorities can deal with shocks using the money supply as instrument. The competitive solutions reveal that the optimal response depend both on the origin of the shocks and the authorities' preferences. The response of the domestic country (assumed as preferring to maintain output) and the foreign country (assumed as preferring to maintain prices) do not always coincide. These differences could be solved by the cooperative solution which theoretically is Pareto improving.

From the comparison between the competitive and the cooperative solutions, we obtain that:

- When dealing with monetary shocks, the cooperative solution results indifferent with independence of the channel of transmission. Therefore, cooperation would not imply a loss of monetary independence. The reason is that when countries cooperate, they react in the same way that if they act individually.

- Secondly, we found that, when dealing with real shocks, cooperation would be always useful when the aggregate demand prevails as channel of transmission. On the contrary, when the interest rate and the real exchange rate prevail, cooperation would be counterproductive when the foreign country suffers the shock.

- Finally, we obtain that when the aggregate demand prevails as channel or transmission, monetary policy cooperation is always useful when dealing with supply-side shocks. The reason is that the cooperation minimizes the cost of using an inappropriate policy (a demand-side policy in order to offset a supply-shock). On the contrary, when the interest rate and the real exchange rate prevail, cooperation is counterproductive.

These result contrast con those in Díaz-Roldán (1998), where the effects of symmetric shocks on economies with identical preferences were analysed. The results showed that monetary cooperation was always useful to deal with monetary shocks, and with supply-side shocks. But when the supply curve is relatively steep, monetary cooperation could became counterproductive to cope with shocks. 
In this paper we study the case of asymmetric shocks and asymmetric preferences. In particular, we obtain that the advantages of monetary policy coordination are greater as greater is the probability of suffering supply shocks. Taking into account the empirical evidence on the EMU, the asymmetry of the shocks has been a question broadly analysed in recent years. But instead of studying the asymmetry of the shocks, it would be more interesting to distinguish among monetary, real and supply shocks. This kind of classification could support the convenience or not of reaching a higher level of monetary coordination, even of joining a monetary union.

There is a scarcity of literature on this issue, which is the line of investigation that could illustrate the results obtained in this paper. Bayoumi and Eichengreen (1993) decompose the observed changes in output and prices of the European countries and the United States, in terms of demand-side and supply-side shocks. As result, they obtain that the supply shocks would prevail in Europe. Karras (1994) analyses the origin of macroeconomic fluctuations in France, Germany and in the UK. He finds that, in spite of that demand shocks explain the short-run economic cycles, supply shocks produce fluctuations both in the short-run and the long-run. Finally, Bergman (1996), in a similar study for Germany, UK, Sweden, USA and Japan, obtains that supply shocks are determinant to explain changes in output and inflation. This kind of results could support the conclusion obtained in this paper: monetary policy coordination could be useful when supply shocks prevail. 


\section{Appendix}

\section{A. I The reduced form (Equations 19 to 22)}

From equation (2) in the main text, we obtain the equilibrium output in the money market. Next, we substitute it into the goods market equilibrium condition (equation (1)). Doing the same for the equations for the rest of the world, and substracting, we obtain the real exchange rate between the domestic country and the foreign country:

$$
\left(e+p^{*}-p\right)=\frac{(m-p)-\left(m^{*}-p^{*}\right)-\delta \theta\left(y-y^{*}\right)-\theta\left(f-f^{*}\right)+\left(q-q^{*}\right)}{2 \beta \theta}
$$

Replacing (A.1) and the world interest rate, $r_{\mathrm{w}}$, from equation (2) into equation (1) we obtain:

$$
y=a_{1} m-a_{1} p-a_{2} m^{*}+a_{2} p^{*}+a_{3} y^{*}+a_{4} f+a_{4} f^{*}+a_{1} q-a_{2} q^{*}
$$

and also for the foreign country:

$$
y^{*}=a_{1} m^{*}-a_{1} p^{*}-a_{2} m+a_{2} p+a_{3} y+a_{4} f^{*}+a_{4} f+a_{1} q^{*}-a_{2} q
$$

Then, substituting (A.1) into the aggregate demand and aggregate supply -equations (15) and (16)- we can obtain the following expressions:

$$
\begin{aligned}
& p=a_{5} m+a_{5} p^{*}-a_{5} m^{*}+a_{6} y-a_{7} y^{*}+a_{5} q-a_{5} q^{*}-a_{8} f+a_{8} f^{*}+a_{9} s \\
& p^{*}=a_{5} m^{*}+a_{5} p-a_{5} m+a_{6} y^{*}-a_{7} y+a_{5} q^{*}-a_{5} q-a_{8} f^{*}+a_{8} f+a_{9} s^{*}
\end{aligned}
$$

where:

$$
\begin{array}{lll}
a_{1}=\frac{2 \theta \alpha+\psi}{\theta(2 \psi+2 \alpha \theta-\delta \psi)}, & a_{2}=\frac{\psi}{\theta(2 \psi+2 \alpha \theta-\delta \psi)}, & a_{3}=\frac{\delta \psi}{2 \psi+2 \alpha \theta-\delta \psi}, \\
a_{4}=\frac{\psi}{2 \psi+2 \alpha \theta-\delta \psi}, & a_{5}=\frac{\lambda \varepsilon \mu}{\lambda \varepsilon \mu+\lambda 2 \beta \theta(1-\lambda \varepsilon \mu)}, & a_{6}=\frac{(2 \beta+\lambda \varepsilon \mu \delta) \theta}{\lambda \varepsilon \mu+\lambda 2 \beta \theta(1-\lambda \varepsilon \mu)}, \\
a_{7}=\frac{\delta \theta \lambda \varepsilon \mu}{\lambda \varepsilon \mu+\lambda 2 \beta \theta(1-\lambda \varepsilon \mu)}, & a_{8}=\frac{\theta \lambda \varepsilon \mu}{\lambda \varepsilon \mu+\lambda 2 \beta \theta(1-\lambda \varepsilon \mu)}, & a_{9}=\frac{2 \beta \theta \lambda}{\lambda \varepsilon \mu+\lambda 2 \beta \theta(1-\lambda \varepsilon \mu)}
\end{array}
$$


with $a_{1}>a_{2}, a_{2}>a_{4}, a_{4}>a_{3}, a_{6}>a_{5}$ and $a_{8}>a_{7}$ and the denominators are positive.

To obtain the equilibrium values for output and prices, we need to solve the system given by equations (A.2) to (A.5):

$$
\left(\begin{array}{cccc}
1 & -a_{3} & a_{1} & -a_{2} \\
-a_{3} & 1 & -a_{2} & a_{1} \\
-a_{6} & a_{7} & 1 & -a_{5} \\
a_{7} & -a_{6} & -a_{5} & 1
\end{array}\right)\left(\begin{array}{l}
y \\
y^{*} \\
p \\
p^{*}
\end{array}\right)=\left(\begin{array}{l}
a_{1} m-a_{2} m^{*}+a_{4} f+a_{4} f^{*}+a_{1} q-a_{2} q^{*} \\
-a_{2} m+a_{1} m^{*}+a_{4} f+a_{4} f^{*}-a_{2} q+a_{1} q^{*} \\
a_{5} m-a_{5} m^{*}-a_{8} f+a_{8} f^{*}+a_{5} q-a_{5} q^{*}+a_{9} s \\
-a_{5} m+a_{5} m^{*}+a_{8} f-a_{8} f^{*}-a_{5} q+a_{5} q^{*}+a_{9} s^{*}
\end{array}\right)
$$

Equations (17) to (20) in the main text are the solution, where the coefficients are:

$$
\begin{aligned}
a= & {\left[a_{5}\left(a_{1}+a_{2}\right)\left(-1+a_{3}+a_{5}-a_{6}\left(a_{1}-a_{2}\right)\right)+a_{1}\left(a_{1} a_{7}-a_{3} a_{5}+a_{2} a_{6}\right)-\right.} \\
& \left.a_{2}\left(a_{3}+a_{2}\left(a_{6}+a_{7}\right)\right)+a_{1}\left(1-a_{5}^{2}+a_{6}\left(a_{1}-a_{2} a_{5}\right)+a_{7}\left(a_{2}-a_{1} a_{5}\right)\right)\right] \Delta \\
b= & {\left[a_{5}\left(a_{1}+a_{2}\right)\left(1-a_{3}-a_{5}-a_{7}\left(a_{1}-a_{2}\right)\right)-a_{2}\left(a_{1} a_{7}-a_{3} a_{5}+a_{2} a_{6}\right)+\right.} \\
& \left.\left.a_{1}\left(a_{3}+a_{2} a_{6}+a_{1} a_{7}\right)\right)-a_{2}\left(1-a_{5}^{2}+a_{6}\left(a_{1}-a_{2} a_{5}\right)+a_{7}\left(a_{2}-a_{1} a_{5}\right)\right)\right] / \Delta \\
c= & {\left[a_{4}\left(1-a_{5}^{2}\left(1+a_{3}\right)+a_{3}+\left(a_{1}+a_{2}\right)\left(a_{6}+a_{7}\right)\left(1-a_{5}\right)\right)+\right.} \\
& \left.a_{8}\left(\left(a_{1}+a_{2}\right)\left(1-a_{5}^{2}\left(1+a_{3}\right)-a_{3}+\left(a_{1}-a_{2}\right)\left(a_{6}+a_{7}\right)\right)\right)\right] / \Delta \\
d= & {\left[a_{4}\left(1-a_{5}^{2}\left(1+a_{3}\right)+a_{3}+\left(a_{1}+a_{2}\right)\left(a_{6}+a_{7}\right)\left(1-a_{5}\right)\right)-\right.} \\
& \left.a_{8}\left(\left(a_{1}+a_{2}\right)\left(1-a_{5}^{2}\left(1+a_{3}\right)-a_{3}+\left(a_{1}-a_{2}\right)\left(a_{6}+a_{7}\right)\right)\right)\right] / \Delta \\
g= & {\left[a_{9}\left(-a_{1}\left(1+a_{3} a_{5}\right)-a_{6}\left(a_{1}^{2}-a_{2}^{2}\right)+a_{2}\left(a_{3}+a_{5}\right)\right)\right] / \Delta } \\
h= & {\left[a_{9}\left(a_{2}\left(1+a_{3} a_{5}\right)-a_{7}\left(a_{1}^{2}-a_{2}^{2}\right)-a_{1}\left(a_{3}+a_{5}\right)\right)\right] / \Delta } \\
i= & {\left[a _ { 5 } \left(\left(1-a_{3}^{2}\right)\left(1-a_{5}\right)+a_{6}\left(\left(1+a_{5}\right)\left(a_{1}-a_{2} a_{3}\right)+2 a_{5}\left(a_{1} a_{3}-a_{2}\right)+\right.\right.\right.} \\
& \left.\left.a_{6}\left(a_{1}^{2}-a_{2}^{2}\right)+a_{7}\left(\left(1+a_{5}\right)\left(a_{2}-a_{1} a_{3}\right)+2 a_{5}\left(a_{2} a_{3}-a_{1}\right)-a_{7}\left(a_{1}^{2}-a_{2}^{2}\right)\right)\right)\right] / \Delta \\
j= & {\left[\left(1-a_{5}\right)\left(a_{6}\left(a_{1} a_{3}-a_{2}\right)+a_{7}\left(a_{2} a_{3}-a_{1}\right)-a_{5}\left(1-a_{3}^{2}\right)\right)\right] / \Delta }
\end{aligned}
$$




$$
\begin{aligned}
& k=\left[a_{4}\left(a_{6}+a_{7}\right)\left(\left(1+a_{3}\right)\left(1+a_{5}\right)+\left(a_{1}+a_{2}\right)\left(a_{6}+a_{7}\right)\right)-\right. \\
& \quad a_{8}\left(1-a_{3}\right)\left(\left(1+a_{3}\right)\left(1-a_{5}\right)+\left(a_{1}-a_{2}\right)\left(a_{6}-a_{7}\right)\right] / \Delta \\
& l=\left[a_{4}\left(a_{6}+a_{7}\right)\left(\left(1+a_{3}\right)\left(1+a_{5}\right)+\left(a_{1}+a_{2}\right)\left(a_{6}+a_{7}\right)\right)+\right. \\
& \quad a_{8}\left(1-a_{3}\right)\left(\left(1+a_{3}\right)\left(1-a_{5}\right)+\left(a_{1}-a_{2}\right)\left(a_{6}-a_{7}\right)\right] / \Delta \\
& n=\left[\left(1-a_{3}^{2}\right)+a_{6}\left(a_{1}-a_{2} a_{3}\right)+a_{7}\left(a_{2}-a_{1} a_{3}\right)\right] / \Delta \\
& \tilde{n}=\left[a_{5}\left(1-a_{3}^{2}\right)+a_{6}\left(a_{2}-a_{1} a_{3}\right)+a_{7}\left(a_{1}-a_{2} a_{3}\right)\right] / \Delta \\
& \text { with } \\
& \Delta=\left[1-a_{5}^{2}\left(1-a_{3}^{2}\right)-a_{3}^{2}+a_{1} a_{6}\left(2+a_{1} a_{6}+2 a_{3} a_{5}\right)+a_{2} a_{7}\left(2+a_{2} a_{7}+2 a_{3} a_{5}\right)\right. \\
& \left.\quad-a_{2} a_{6}\left(2 a_{5}+a_{2} a_{6}+2 a_{3}\right)-a_{1} a_{7}\left(2 a_{5}+a_{1} a_{7}+2 a_{3}\right)\right]>0
\end{aligned}
$$

\section{A.II The coefficients of the reaction functions}

THE LOCOMOTIVE EFFECT

For a country interested in maintaining prices $\sigma>1$ and, then, we have:

$$
\begin{aligned}
& R_{p, 1}=\frac{2 a b+2 i j \sigma}{2 a^{2}+2 i^{2} \sigma}, \quad R_{p, 2}=\frac{2 a c+2 i k \sigma}{2 a^{2}+2 i^{2} \sigma}, \quad R_{p, 3}=\frac{2 a d+2 i l \sigma}{2 a^{2}+2 i^{2} \sigma} \\
& R_{p, 4}=\frac{2 a g+2 i n \sigma}{2 a^{2}+2 i^{2} \sigma}, \quad R_{p, 5}=\frac{2 a h+2 i \tilde{n} \sigma}{2 a^{2}+2 i^{2} \sigma}
\end{aligned}
$$

On the other hand, for a country interested in maintaining output the coefficients are identical except for $\sigma<1$.

For the foreign country, the coefficients are the same than for the domestic country except for $\sigma^{*}>1$ and $\sigma^{*}<1$, depending on the preferences for prices or output, respectively. 
THE BEGGAR-THY-NEIGHBOUR EFFECT

For a country interested in maintaining prices $\sigma>1$ and, then, we have:

$$
\begin{aligned}
& R_{p, 1}^{\prime}=\frac{2 a b+2 i j \sigma}{2 a^{2}+2 i^{2} \sigma}, \quad R_{p, 2}^{\prime}=\frac{2 a c+2 i k \sigma}{2 a^{2}+2 i^{2} \sigma}, \quad R_{p, 3}^{\prime}=\frac{2 a d-2 i l \sigma}{2 a^{2}+2 i^{2} \sigma} \\
& R_{p, 4}^{\prime}=\frac{2 a g-2 i n \sigma}{2 a^{2}+2 i^{2} \sigma}, \quad R_{p, 5}^{\prime}=\frac{2 a h-2 i \tilde{n} \sigma}{2 a^{2}+2 i^{2} \sigma}
\end{aligned}
$$

On the other hand, for a country interested in maintaining output the coefficients are identical except for $\sigma<1$.

For the foreign country, the coefficients are the same than for the domestic country except for $\sigma^{*}>1$ and $\sigma^{*}<1$, depending on the preferences for prices or output, respectively.

\section{A. III The Nash-Cournot solution}

THE LOCOMOTIVE EFFECT

$$
\begin{aligned}
& N_{1}=\frac{R_{y, 2}-R_{y, 1} R_{p, 2}^{*}}{1-R_{y, 1} R_{p, 2}^{*}} \quad N_{1}^{*}=\frac{R_{p, 2}^{*}-R_{y, 2} R_{p, 1}^{*}}{1-R_{y, 1} R_{p, 2}^{*}} \\
& N_{2}=\frac{R_{y, 3}-R_{y, 1} R_{p, 3}^{*}}{1-R_{y, 1} R_{p, 2}^{*}} \quad N_{2}^{*}=\frac{R_{p, 3}^{*}-R_{y, 3} R_{p, 1}^{*}}{1-R_{y, 1} R_{p, 2}^{*}} \\
& N_{3}=\frac{R_{y, 4}+R_{y, 1} R_{p, 4}^{\star}}{1-R_{y, 1} R_{p, 2}^{*}} \quad N_{3}^{*}=\frac{R_{p, 4}^{*}+R_{y, 4} R_{p, 1}^{*}}{1-R_{y, 1} R_{p, 2}^{*}} \\
& N_{4}=\frac{R_{y, 5}+R_{y, 1} R_{p, 5}^{*}}{1-R_{y, 1} R_{p, 2}^{*}} \quad N_{4}^{*}=\frac{R_{p, 5}^{*}+R_{y, 5} R_{p, 1}^{*}}{1-R_{y, 1} R_{p, 2}^{*}}
\end{aligned}
$$

THE BEGGAR-THY-NEIGHBOUR EFFECT 


$$
\begin{aligned}
& N_{1}^{\prime}=\frac{R_{y, 2}^{\prime}-R_{y, 1}^{\prime} R_{p, 2}^{\prime *}}{1-R_{y, 1}^{\prime} R_{p, 2}^{\prime *}} \quad N_{1}^{\prime *}=\frac{R_{p, 2}^{\prime *}-R_{y, 2}^{\prime} R_{p, 1}^{\prime *}}{1-R_{y, 1}^{\prime} R_{p, 2}^{\prime \prime}} \\
& N_{2}^{\prime}=\frac{R_{y, 3}^{\prime}-R_{y, 1}^{\prime} R_{p, 3}^{\prime}{ }^{*}}{1-R_{y, 1}^{\prime} R_{p, 2}^{\prime *}} \quad N_{2}^{\prime *}=\frac{R_{p, 3}^{\prime *}-R_{y, 3}^{\prime} R_{p, 1}^{\prime *}}{1-R_{y, 1}^{\prime} R_{p, 2}^{\prime *}} \\
& N_{3}^{\prime}=\frac{R_{y, 4}^{\prime}-R_{y, 1}^{\prime} R_{p, 4}^{\prime *}}{1-R_{y, 1}^{\prime} R_{p, 2}^{\prime *}} \quad N_{3}^{\prime *}=\frac{R_{p, 4}^{\prime *}-R_{y, 4}^{\prime} R_{p, 1}^{\prime *}}{1-R_{y, 1}^{\prime} R_{p, 2}^{\prime \prime}} \\
& N_{4}^{\prime}=\frac{R_{y, 5}^{\prime}-R_{y, 1}^{\prime} R_{p, 5}^{\prime}{ }^{*}}{1-R_{y, 1}^{\prime} R_{p, 2}^{\prime *}} \quad N_{4}^{\prime *}=\frac{R_{p, 5}^{\prime *}-R_{y, 5}^{\prime} R_{p, 1}^{\prime *}}{1-R_{y, 1}^{\prime} R_{p, 2}^{\prime *}}
\end{aligned}
$$

\section{A. IV The Nash-Stackelberg solution}

THE LOCOMOTIVE EFFECT

$$
\begin{gathered}
S_{1}^{*}=\frac{\left(a-b R_{y, 1}\right)\left(b-d R_{y, 2}\right)+\left(i-j R_{y, 1}\right)\left(j-l R_{y, 2} \sigma^{*}\right)}{\left(a-b R_{y, 1}\right)^{2}-\left(i-j R_{y, 1}\right)^{2} \sigma^{*}} \\
S_{2}^{*}=\frac{\left(a-b R_{y, 1}\right)\left(b-c R_{y, 3}\right)+\left(i-j R_{y, 1}\right)\left(j-k R_{y, 3} \sigma^{*}\right)}{\left(a-b R_{y, 1}\right)^{2}-\left(i-j R_{y, 1}\right)^{2} \sigma^{*}} \\
S_{3}^{*}=\frac{\left.\left.\left(a-b R_{y, 1}\right)(b-h) R_{y, 4}\right)-\left(i-j R_{y, 1}\right)(j+\tilde{n}) R_{y, 4} \sigma^{*}\right)}{\left(a-b R_{y, 1}\right)^{2}-\left(i-j R_{y, 1}\right)^{2} \sigma^{*}} \\
S_{4}^{*}=\frac{\left(a-b R_{y, 1}\right)\left(g-b R_{y, 5}\right)-\left(i-j R_{y, 1}\right)\left(j+n R_{y, 5} \sigma^{*}\right)}{\left(a-b R_{y, 1}\right)^{2}-\left(i-j R_{y, 1}\right)^{2} \sigma^{*}} \\
S_{1}=\frac{a\left(c \pm b S_{1}^{*}\right)+i \sigma\left(k \pm j S_{1}^{*}\right)}{a^{2}+i^{2} \sigma}
\end{gathered}
$$




$$
\begin{aligned}
& S_{2}=\frac{a\left(d \pm b S_{2}^{*}\right)+i \sigma\left(l \pm j S_{2}^{*}\right)}{a^{2}+i^{2} \sigma} \\
& S_{3}=\frac{a\left(g \pm b S_{3}^{*}\right)+i \sigma\left(j \pm n S_{3}^{*}\right)}{a^{2}+i^{2} \sigma} \\
& S_{4}=\frac{a\left(h \pm b S_{4}^{*}\right)+i \sigma\left(j \pm \tilde{n} S_{4}^{*}\right)}{a^{2}+i^{2} \sigma}
\end{aligned}
$$

THE BEGGAR-THY-NEIGHBOUR EFFECT

$$
\begin{gathered}
S_{1}^{\prime *}=\frac{\left(a-b R_{y, 1}\right)\left(d-b R_{y, 2}\right)-\left(i-j R_{y, 1}\right)(l+j) R_{y, 2} \sigma^{*}}{\left(a-b R_{y, 1}\right)^{2}-\left(i-j R_{y, 1}\right)^{2} \sigma^{*}} \\
S_{2}^{\prime *}=\frac{\left(a-b R_{y, 1}\right)\left(b R_{y, 3}-c\right)+\left(i-j R_{y, 1}\right)\left(j R_{y, 3}-k\right) \sigma^{*}}{\left(a-b R_{y, 1}\right)^{2}-\left(i-j R_{y, 1}\right)^{2} \sigma^{*}} \\
S_{3}^{{ }^{*}}=\frac{\left(a-b R_{y, 1}\right)\left(b R_{y, 4}+h\right)-\left(i-j R_{y, 1}\right)\left(j R_{y, 4}+\tilde{n}\right) \sigma^{*}}{\left(a-b R_{y, 1}\right)^{2}-\left(i-j R_{y, 1}\right)^{2} \sigma^{*}} \\
S_{4}^{{ }^{*}}=\frac{\left(a-b R_{y, 1}\right)\left(g+b R_{y, 5}\right)-\left(i-j R_{y, 1}\right)\left(n-j R_{y, 5}\right) \sigma^{*}}{\left(a-b R_{y, 1}\right)^{2}-\left(i-j R_{y, 1}\right)^{2} \sigma^{*}} \\
S_{1}^{\prime}=\frac{a\left(c \pm b S_{1}^{\prime *}\right)+i \sigma\left(k \pm j S_{1}^{\prime *}\right)}{a^{2}+i^{2} \sigma} \\
S_{2}^{\prime}=\frac{a\left(d \pm b S_{2}^{\prime *}\right)+i \sigma\left(l \pm j S_{2}^{*}\right)}{a^{2}+i^{2} \sigma}
\end{gathered}
$$




$$
\begin{aligned}
& S_{3}^{\prime}=\frac{a\left(g \pm b S_{3}^{*}\right)+i \sigma\left(j \pm n S_{3}^{\prime *}\right)}{a^{2}+i^{2} \sigma} \\
& S_{4}^{\prime}=\frac{a\left(h \pm b S_{4}^{\prime *}\right)+i \sigma\left(j \pm \tilde{n} S_{4}^{\prime *}\right)}{a^{2}+i^{2} \sigma}
\end{aligned}
$$

\section{A. V The cooperative solution}

THE LOCOMOTIVE EFFECT

$$
\begin{gathered}
C_{1}=\frac{\left(a c+b d+i k \sigma+j l \sigma^{*}\right)-\left(2 a b+i j\left(\sigma+\sigma^{*}\right)\right)\left(b c+a d+j k \sigma+i l \sigma^{*}\right)}{\left(2 a b+i j\left(\sigma+\sigma^{*}\right)\right)^{2}-\left(a^{2}+b^{2}+\left(i^{2}+j^{2}\right) \sigma\right)} \\
C_{2}=\frac{\left(b c+a d+i l \sigma+j k \sigma^{*}\right)-\left(2 a b+i j\left(\sigma+\sigma^{*}\right)\right)\left(a c+b d+j l \sigma+i k \sigma^{*}\right)}{\left(2 a b+i j\left(\sigma+\sigma^{*}\right)\right)^{2}-\left(a^{2}+b^{2}+\left(i^{2}+j^{2}\right) \sigma\right)} \\
C_{3}=\frac{\left(-b g-a h+i \tilde{n} \sigma+j n \sigma^{*}\right)-\left(2 a b+i j\left(\sigma+\sigma^{*}\right)\right)\left(-b g-a h+j n \sigma+i n \tilde{n} \sigma^{*}\right)}{\left(2 a b+i j\left(\sigma+\sigma^{*}\right)\right)^{2}-\left(a^{2}+b^{2}+\left(i^{2}+j^{2}\right) \sigma\right)} \\
C_{4}=\frac{\left(-a g-b h+i n \sigma+j \tilde{n} \sigma^{*}\right)-\left(2 a b+i j\left(\sigma+\sigma^{*}\right)\right)\left(-a g-b h+j \tilde{n} \sigma+i n \sigma^{*}\right)}{\left(2 a b+i j\left(\sigma+\sigma^{*}\right)\right)^{2}-\left(a^{2}+b^{2}+\left(i^{2}+j^{2}\right) \sigma\right)} \\
C_{1}^{*}=\frac{\left(b c+a d+j k \sigma+i l \sigma^{*}\right)-\left(2 a b+i j\left(\sigma+\sigma^{*}\right)\right)\left(a c+b d+i k \sigma+j l \sigma^{*}\right)}{\left(2 a b+i j\left(\sigma+\sigma^{*}\right)\right)^{2}-\left(a^{2}+b^{2}+\left(i^{2}+j^{2}\right) \sigma\right)} \\
C_{2}^{*}=\frac{\left(a c+b d+j l \sigma+i k \sigma^{*}\right)-\left(2 a b+i j\left(\sigma+\sigma^{*}\right)\right)\left(b c+a d+i l \sigma+j k \sigma^{*}\right)}{\left(2 a b+i j\left(\sigma+\sigma^{*}\right)\right)^{2}-\left(a^{2}+b^{2}+\left(i^{2}+j^{2}\right) \sigma\right)}
\end{gathered}
$$




$$
\begin{aligned}
& C_{3}^{*}=\frac{\left(-b g-a h+j n \sigma+i \tilde{n} \sigma^{*}\right)-\left(2 a b+i j\left(\sigma+\sigma^{*}\right)\right)\left(-b g-a h+i \tilde{n} \sigma+j n \sigma^{*}\right)}{\left(2 a b+i j\left(\sigma+\sigma^{*}\right)\right)^{2}-\left(a^{2}+b^{2}+\left(i^{2}+j^{2}\right) \sigma\right)} \\
& C_{4}^{*}=\frac{\left(-a g-b h+j \tilde{n} \sigma+i n \sigma^{*}\right)-\left(2 a b+i j\left(\sigma+\sigma^{*}\right)\right)\left(-a g-b h+i n \sigma+j \tilde{n} \sigma^{*}\right)}{\left(2 a b+i j\left(\sigma+\sigma^{*}\right)\right)^{2}-\left(a^{2}+b^{2}+\left(i^{2}+j^{2}\right) \sigma\right)}
\end{aligned}
$$

THE BEGGAR-THY-NEIGHBOUR EFFECT

$$
\begin{gathered}
C_{1}^{\prime}=\frac{\left(a c+b d+i k \sigma+j l \sigma^{*}\right)-\left(2 a b+i j\left(\sigma+\sigma^{*}\right)\right)\left(b c+a d+j k \sigma+i l \sigma^{*}\right)}{\left(2 a b+i j\left(\sigma+\sigma^{*}\right)\right)^{2}-\left(a^{2}+b^{2}+\left(i^{2}+j^{2}\right) \sigma\right)} \\
C_{2}^{\prime}=\frac{\left(2 a b+i j\left(\sigma+\sigma^{*}\right)\right)\left(a c+b d+j l \sigma+i k \sigma^{*}\right)-\left(b c+a d+i l \sigma+j k \sigma^{*}\right)}{\left(2 a b+i j\left(\sigma+\sigma^{*}\right)\right)^{2}-\left(a^{2}+b^{2}+\left(i^{2}+j^{2}\right) \sigma\right)} \\
C_{3}^{\prime}=\frac{\left(a g-b h-i n \sigma+j \tilde{n} \sigma^{*}\right)-\left(2 a b+i j\left(\sigma+\sigma^{*}\right)\right)\left(-b g-a h+j n \sigma-i \tilde{n} \sigma^{*}\right)}{\left(2 a b+i j\left(\sigma+\sigma^{*}\right)\right)^{2}-\left(a^{2}+b^{2}+\left(i^{2}+j^{2}\right) \sigma\right)} \\
C_{4}^{\prime}=\frac{\left(-b g+a h-i \tilde{n} \sigma+j n \sigma^{*}\right)-\left(2 a b+i j\left(\sigma+\sigma^{*}\right)\right)\left(-a g+b h-j \tilde{n} \sigma+i n \sigma^{*}\right)}{\left(2 a b+i j\left(\sigma+\sigma^{*}\right)\right)^{2}-\left(a^{2}+b^{2}+\left(i^{2}+j^{2}\right) \sigma\right)} \\
C_{1}^{\prime *}=\frac{\left(2 a b+i j\left(\sigma+\sigma^{*}\right)\right)\left(a c+b d+i k \sigma+j l \sigma^{*}\right)-\left(b c+a d+j k \sigma+i l \sigma^{*}\right)}{\left(2 a b+i j\left(\sigma+\sigma^{*}\right)\right)^{2}-\left(a^{2}+b^{2}+\left(i^{2}+j^{2}\right) \sigma\right)} \\
C_{3}^{\prime *}=\frac{\left(-a c-b d-j l \sigma-i k \sigma^{*}\right)-\left(2 a b+i j\left(\sigma+\sigma^{*}\right)\right)\left(b c+a d+i l \sigma+j k \sigma^{*}\right)}{\left(2 a b+i j\left(\sigma+\sigma^{*}\right)\right)^{2}-\left(a^{2}+b^{2}+\left(i^{2}+j^{2}\right) \sigma\right)} \\
\left(2 a b+i j\left(\sigma+\sigma^{*}\right)\right)^{2}-\left(a^{2}+b^{2}+\left(i^{2}+j^{2}\right) \sigma\right)
\end{gathered}
$$




$$
C_{4}^{\prime *}=\frac{\left(-b g+a h-i \tilde{n} \sigma+j n \sigma^{*}\right)-\left(2 a b+i j\left(\sigma+\sigma^{*}\right)\right)\left(-a g+b h-j \tilde{n} \sigma+i n \sigma^{*}\right)}{\left(2 a b+i j\left(\sigma+\sigma^{*}\right)\right)^{2}-\left(a^{2}+b^{2}+\left(i^{2}+j^{2}\right) \sigma\right)}
$$

\section{A. VI Externalities}

THE LOCOMOTIVE EFFECT

$$
\begin{gathered}
\frac{\partial L}{\partial m^{*}}=2 b\left(a m+b m^{*}+c f+d f^{*}+a q+b q^{*}-g s-h s^{*}\right)+ \\
2 j \sigma\left(i m+j m^{*}+k f+l f^{*}+i q+j q^{*}+n s+\tilde{n} s^{*}\right) \neq 0 \\
\frac{\partial L^{*}}{\partial m}=2 b\left(a m^{*}+b m+c f^{*}+d f+a q^{*}+b q-g s^{*}-h s\right)+ \\
2 j \sigma^{*}\left(i m^{*}+j m+k f^{*}+l f+i q^{*}+j q+n s^{*}+\tilde{n} s\right) \neq 0
\end{gathered}
$$

THE BEGGAR-THY-NEIGHBOUR EFFECT

$$
\begin{gathered}
\frac{\partial L}{\partial m^{*}}=-2 b\left(a m-b m^{*}+c f-d f^{*}+a q-b q^{*}-g s-h s^{*}\right)- \\
2 j \sigma\left(i m-j m^{*}+k f+l f^{*}+i q-j q^{*}+n s+\tilde{n} s^{*}\right) \neq 0 \\
\frac{\partial L^{*}}{\partial m}=-2 b\left(a m^{*}-b m+c f^{*}-d f+a q^{*}-b q-g s^{*}-h s\right)- \\
2 j \sigma^{*}\left(i m^{*}-j m+k f^{*}+l f+i q^{*}-j q+n s^{*}+\tilde{n} s\right) \neq 0
\end{gathered}
$$




\section{References}

[1] Bajo, O. and Vegara, D. (1997): "Integración monetaria en Europa: Teoría y evidencia empírica", Hacienda Pública Española 140, 19-37.

[2] Ballabriga, F., Sebastián, M. and Vallés, J. (1993): "Interdependence of EC economies: A VAR approach", Working Paper 9314, Banco de España, Madrid.

[3] Bayoumi, T. and Eichengreen, B. (1993): "Shocking aspects of European monetary integration", in Torres, F. and Giavazzi, F. (eds.): Adjustment and growth in the European Monetary Union, Cambridge University Press, Cambridge, 193-229.

[4] Bergman, M. (1996): "International evidence on the sources of macroeconomic fluctuations", European Economic Review 40, 12371258.

[5] Bryant, R. C. (1995): "International cooperation in the making of national macroeconomic policies: Where do we stand?", in Kenen, P. B. (ed. ): Understanding interdependence. The macroeconomics of the open economy, Princeton University Press, Princeton.

[6] Canzoneri, M. and Gray, J. (1985): "Monetary policy games and the consequences of non cooperative behaviour", International Economic Review 26, 547-564.

[7] Cohen, D. and Wyplosz, C. (1989): "The European Monetary Union: An agnostic evaluation", in Bryant, R. et al. (eds.): Macroeconomic policies in an interdependent world, International Monetary Fund, Washington, DC, 311-337.

[8] Cooper, R. N. (1985): "Economic interdependence and coordination of economic policies", in Jones, R. and Kenen, P. (eds.): Handbook of International Economics (vol II), North-Holland, Amsterdam, 11951234.

[9] Corden, W. M. (1985): "Macroeconomic policy interaction under flexible exchange rates: A two-country model", Economica 52, 9-23. 
[10] Corden,W. M. (1986): "On transmission and coordination under flexible exchange rates", in Buiter, W. H. and Marston, R. C. (eds.): International Economic Policy Coordination, Cambridge University Press, Cambridge, 8-36.

[11] Currie, D. and Levine, P. (1986): "Macroeconomic policy design in an interdependent world", in Buiter, W. H. and Marston, R. C. (eds.): International Economic Policy Coordination, Cambridge University Press, Cambridge, 228-273.

[12] De Grauwe, P. and Vanhaverbeke, W. (1993): "Is Europe an optimum currency area?: Evidence from regional data", en Masson, P. and Taylor, M. (eds.): Policy issues in the operation of currency unions, Cambridge University Press, Cambridge, 111-129.

[13] Díaz Roldán, C. (1998): "La coordinación internacional de la política monetaria en presencia de perturbaciones simétricas: ¿Resulta beneficioso cooperar?", Working Paper 9808, Department of Economics, Universidad Pública de Navarra.

[14] Douven, R. C. and Plasmans, J. E. J. (1995): "Convergence and international policy coordination in the EU: A dynamic games approach", Report 95/325, Universiteit Antwerpen.

[15] Erkel-Rousse, H. and Mélitz, J. (1995): "New empirical evidence en the costs of European Monetary Union", Discussion Paper 1169, Centre for Economic Policy Research, Londres.

[16] Frankel, J. A. and Rockett, K. E. (1988): "International macroeconomic policy coordination when policymakers do not agree on the true model", American Economic Review 78, 318-340.

[17] Frenkel, J. A.; Goldstein, M. and Masson, P. (1988): "International coordination of economic policies: Scope, methods and effects", in Guth, W. (ed.): Economic Policy Coordination, International Monetary Fund, Washington, D. C.

[18] Gutiérrez, M. J. (1993): "Monetary cooperation among countries: A survey", Working Paper 93.20, Universidad del País Vasco. 
[19] Hamada, K. (1976): "A strategic analysis of monetary interdependence", Journal of Political Economy 84, 877-895.

[20] Helg, R.; Manasse, P.; Monacelli, T. and Rovelli, R. (1995): "How much (a)symmetry in Europe? Evidence from industrial sectors", European Economic Review 39, 1017-1041.

[21] Hughes Hallet, A. and Ma, Y. (1995): "Economic cooperation within Europe: Lessons from the monetary arrangements in the 1990s', Discussion Paper 1190, Centre for Economic Policy Research, Londres.

[22] Karras, G. (1994): "Sources of business cycles in Europe: 1960-1988. Evidence from France, Germany, and the United Kingdom", European Economic Review 38, 1763-1778.

[23] Kehoe, P. (1987): "Coordination of fiscal policies in a world economy", Journal of Monetary Economics 19, 349-376.

[24] Layard, R., Nickell, S. and Jackman, R. (1991): Unemployment: Macroeconomic performance and the labour market, Oxford University Press, Oxford.

[25] Mundell, R.A. (1961): "A theory of optimum currency areas", American Economic Review 51, 657-665.

[26] Mundell, R.A. (1964): "A reply: Capital mobility and size", Canadian Journal of Economics and Political Science 30, 421-431.

[27] Nickell, S. (1990): "Unemployment: A survey", The Economic Journal, 100, 391-439.

[28] Oudiz, G. y Sachs, J. (1984): "Macroeconomic policy coordination among the industrial economies", Brookings Papers on Economic Activity 1, 1-75.

[29] Sibert, A. (1997): "Monetary integration and economic convergence", Discussion Paper 1561, Centre for Economic Policy Research, London.

[30] Viñals, J. and Jimeno, J. F. (1996): "Monetary union and European unemployment", Working Paper 9624, Banco de España, Madrid. 
[31] Weber, A. (1991): "EMU and asymmetries and adjustment problems in the EMS: Some empirical evidence", European Economy, Special edition No. 1, 187-207. 